\title{
Modulation of tumor growth by inhibitory $F c \gamma$ receptor expressed by human melanoma cells
}

\author{
Lydie Cassard, ${ }^{1}$ Joël F.G. Cohen-Solal, ${ }^{1}$ Annie Galinha, ${ }^{1}$ Xavier Sastre-Garau, ${ }^{2}$ \\ Claire Mathiot, ${ }^{3}$ Jérôme Galon, ${ }^{1}$ Thierry Dorval, ${ }^{4}$ Alain Bernheim, ${ }^{5}$ Wolf H. Fridman, ${ }^{1}$ \\ and Catherine Sautès-Fridman ${ }^{1}$
}
${ }^{1}$ Unité d'Immunologie Cellulaire et Clinique, Institut National de la Santé et de la Recherche Médicale (INSERM) U 255 and Université Pierre et Marie Curie Paris VI, Centre de Recherches Biomédicales des Cordeliers, Paris, France
${ }^{2}$ Département de Anatomopathologie,
${ }^{3}$ Laboratoire d'Hématologie, and
${ }^{4}$ Service de Médecine Oncologique, Institut Curie, Paris, France
${ }^{5}$ Centre National de la Recherche Scientifique Unité Mixte de Recherche 1599, Laboratoire de Cytogénétique, Institut Gustave Roussy, Villejuif, France

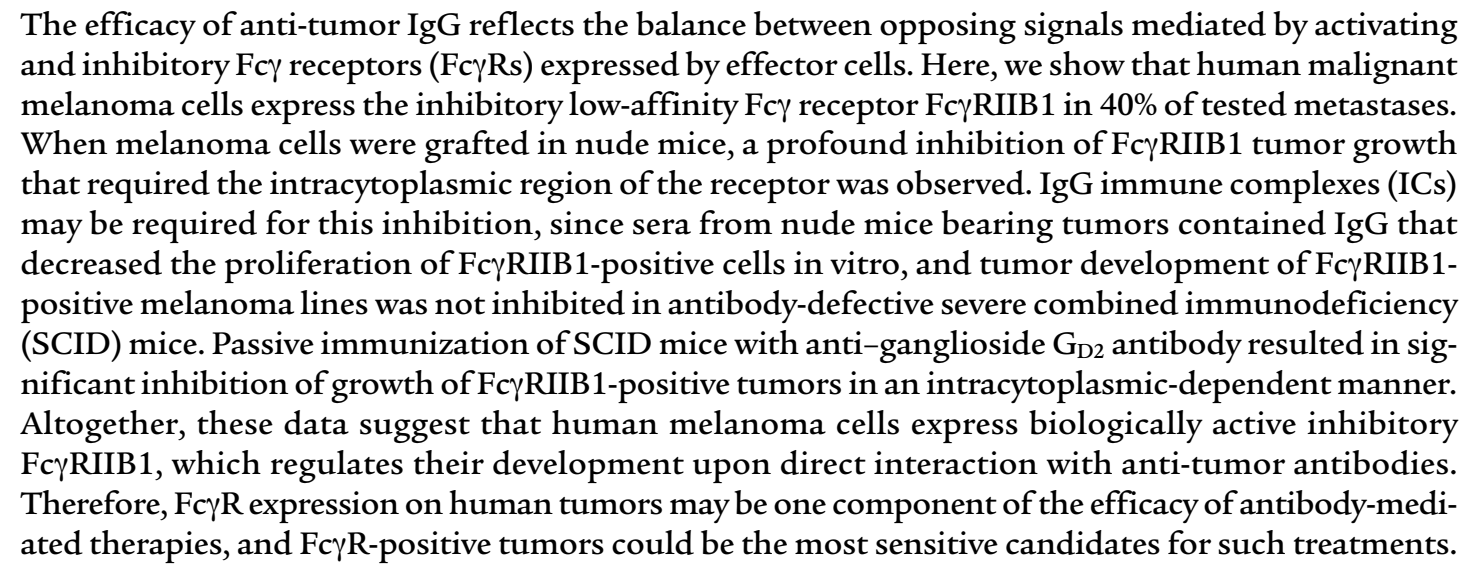
J. Clin. Invest. 110:1549-1557 (2002). doi:10.1172/JCI200215454.

\section{Introduction}

The $\mathrm{F} c \gamma$ receptors ( $\mathrm{Fc} \gamma \mathrm{Rs}$ ) expressed on hematopoietic cells play a key role in immune defenses by linking humoral and cellular immunity (1). Fc $\gamma$ Rs display coordinate and opposing roles in immune responses depending on their cytoplasmic region and/or their associated chains. Indeed, the activating receptors contain an immunoreceptor tyrosine-based activation motif (ITAM) and initiate inflammatory, cytolytic, and phagocytic activities of immune effector cells. In contrast, the inhibitory receptors that downmodulate the immune responses contain an immunoreceptor tyrosine-based inhibitory motif (ITIM) $(2,3)$. Three

Received for publication March 13, 2002, and accepted in revised form October 1, 2002.

Address correspondence to: Catherine Sautès-Fridman, INSERM U255, Centre de Recherches Biomédicales des Cordeliers, 15 rue de l'Ecole de Médecine, 75006 Paris, France. Phone: 33-1-53-10-04-03; Fax: 33-1-40-51-04-20; E-mail: catherine.fridman@u255.bhdc.jussieu.fr.

Conflict of interest: The authors have declared that no conflict of interest exists.

Nonstandard abbreviations used: $\mathrm{F}_{\mathrm{C}} \gamma$ receptor $(\mathrm{F} \gamma \mathrm{R})$; immunoreceptor tyrosine-based activation motif (ITAM); immunoreceptor tyrosine-based inhibitory motif (ITIM); immune complex (IC); antibody-dependent cellular cytotoxicity (ADCC); severe combined immunodeficiency (SCID). categories of Fc $\gamma R$ exist: Fc $\gamma R$ I has high affinity for monomeric IgG, whereas FcyRII and FcyRIII exhibit low affinity for monomeric IgG but avidly bind IgGcontaining immune complexes (ICs). Both in mice and in humans (4), two isoforms of the inhibitory Fc $\gamma$ RIIB (FcrRIIB1 and Fc $\gamma$ RIIB2) are produced by an alternative splicing, which generates a 47 -amino acid insert in the intracellular domain of Fc $\gamma$ RIIB1.

Antibodies directed against neoplastic cells provide new therapeutic approaches against various malignancies, including lymphoma, leukemia, melanoma, and breast and colorectal carcinoma $(5,6)$. There is increasing evidence that the $\mathrm{Fc}$ portion of the anti-tumor IgG is a major component of their therapeutic activity, along with other mechanisms such as activation of apoptosis, blockade of signaling pathways, or masking of tumor antigens. Thus, by binding to activating FcyRs expressed by immune effector cells, such as macrophages, monocytes, neutrophils, or NK cells, tumor-specific antibodies trigger the destruction of malignant cells via antibody-dependent cellular cytotoxicity (ADCC) or phagocytosis $(7,8)$. Recent experiments have shown that inhibitory $F c \gamma R$ decreases the in vivo efficacy of antibodies against tumors. Indeed, the use of mAb's to eradicate a variety of tumors in mice reveals that the Fc $\gamma$ RIIB inhibitory receptor expressed on effector cells 
is a potent regulator of ADCC in vivo, downmodulating the activation of monocytes and macrophages via ITAM-containing F $\gamma \gamma R$ (9).

It has previously been suspected that human and mouse tumors from nonhematopoietic tissues may express low-affinity Fc $\gamma \mathrm{R}(10)$. However, whether the Fc $\gamma$ R-expressing cells originated as tumor or inflammatory cells was debated. It was difficult to answer this question because tumor cells lose $\mathrm{F} c \gamma \mathrm{R}$ expression in culture (11). Interestingly, the expression of $\mathrm{Fc} \gamma \mathrm{R}$ can be recovered after a single passage of tumor cells in vivo, and some tumor cell lines expressed $\mathrm{Fc} \gamma \mathrm{R}$ (12). We report here, for the first time to our knowledge, that human metastatic melanoma cells express inhibitory FcyRIIB1 in vivo and ex vivo. This expression is associated with an inhibition of development of melanoma tumors grafted subcutaneously in nude mice, but not in severe combined immunodeficiency (SCID) mice. The anti-G $\mathrm{G}_{\mathrm{D} 2} \mathrm{mAb}$ IgG3, whose $\mathrm{Fc}$ portion binds to human tumor FcyRIIB1 but not to host-cell mouse Fc $\gamma$ Rs, reduced growth of Fc $\gamma$ RIIB1-positive tumors when it was inoculated in SCID mice. Altogether, our data suggest a novel mechanism by which anti-tumor IgG might directly regulate tumor development.

\section{Methods}

Human melanoma tumors and cell lines. The human malignant melanoma lines A375 and HT144 (American Type Culture Collection, Manassas, Virginia, USA) were maintained in RPMI 1640 supplemented with $10 \%$ FCS, 2 mM L-glutamine, $1 \%$ sodium pyruvate, and $1 \%$ penicillin-streptomycin. A375 cells, which do not express FcyRII mRNA, were stably transfected (13) with pBR322-zeo vector containing human FcyRIIB1 (A375IIB1), Fc $\gamma$ RIIB2 (A375IIB2), or Fc $\gamma$ RIIA (A375IIA) cDNAs. HT144 cells were stably transfected with the same vector containing human Fc $\gamma$ RIIB1 cDNA (HT144IIB1) or with FcyRIIB(Cyto-) cDNA, which contains no cytoplasmic residues beyond the juxtamembrane region [HT144IIB $\left.\left(\mathrm{Cyto}^{-}\right)\right]$. Transfectants were cloned by limiting dilution and tested for Fc $\gamma \mathrm{RII}$ expression by flow cytometry. The human lymphoma ST486 (American Type Culture Collection) was cultured in DMEM supplemented with 10\% FCS, $2 \mathrm{mM}$ L-glutamine, $5 \%$ sodium pyruvate, $20 \mu \mathrm{M} 2$-mercaptoethanol, and $1 \%$ penicillin-streptomycin.

The cutaneous (patient 201), liver (patients 212, 721, and 926), or lymph node (patient 193) metastasis from patients with melanoma was analyzed. The 721 cell line was derived by culturing liver metastasis in DMEM supplemented with 10\% FCS, 2 mM L-glutamine, $1 \%$ sodium pyruvate, and $1 \%$ penicillin-streptomycin. After 1 week of culture, Fc $\gamma$ RII-positive and negative clones were selected using anti-Fc $\gamma$ RIIA $+B$ mAb (AT10) (14) coupled to magnetic beads (Immunotech, Marseille, France).

In vivo tumor growth. Melanoma cells were injected subcutaneously into Swiss nude mice or into CB17 SCID mice. Tumor development at the site of injec- tion was evaluated twice a week. Tumor volume (in $\mathrm{mm}^{3}$ ) was estimated from the length, $a$, and width, $b$, of the tumor: volume $=a b^{2} / 2$. The mice were bled 1 week before and 14 days after tumor cell injection, and IgGs were purified by protein A-Sepharose column (Pharmacia Biotech AB, Uppsala, Sweden). In some experiments, SCID mice were inoculated subcutaneously with melanoma cells on day 0 and intravenously with $50 \mu \mathrm{g}$ anti- $\mathrm{G}_{\mathrm{D} 2} \mathrm{mAb} 7 \mathrm{~A} 4$ (15) or PBS on days $0,3,6,9,13$, and 16 .

Flow cytometry analysis. Cells were incubated with AT10, anti-FcyRIIA mAb IV.3 (16), anti-G $\mathrm{G}_{\mathrm{D} 2} \mathrm{mAb}$ 7A4, $\mathrm{Mel} / 14 \mathrm{mAb}$ (17), a 1:10 dilution of sera from mice or with medium alone followed by FITC-conjugated goat anti-mouse IgG Ab (FITC-GAM) (Jackson ImmunoResearch Laboratories Inc., West Grove, Pennsylvania, USA). In some experiments, cells were incubated with FITC-coupled anti-HLADR mAb or FITC-coupled isotypic control IgG2a (Immunotech). Flow cytometry analysis was performed with a FACScan (Becton Dickinson, Mountain View, California, USA.)

Cytogenetics. Cell lines were incubated with colcemid (GIBCO BRL; Life Technologies Inc., Cergy Pontoise, France) for 2 hours, then with buffer containing 0.075 $\mathrm{M} \mathrm{KCl}$, and fixed with methanol/acetic acid (3 vol/1 vol). After spreading, $\mathrm{R}$ banding was performed and analyzed using a digital imaging system.

Western blot analysis. The FcyRIIs were immunoprecipitated with AT10 as described previously (13). In some experiments, HT144IIB1 cells $\left(10^{7} / \mathrm{ml}\right)$ were incubated with $100 \mu \mathrm{M}$ pervanadate for 10 minutes at $37^{\circ} \mathrm{C}$. Cells were centrifuged and lysed, and Fc $\gamma$ RIIB1 was immunoprecipitated as above. Immunoprecipitated material was fractioned by SDS-PAGE (Bio-Rad Laboratories Inc., Hercules, California, USA), transferred and Western blotted with anti-SHIP1, anti-SHIP2 (Upstate Biotechnology Inc., Lake Placid, New York, USA), anti-SHP1, anti-SHP2, or anti-phosphotyrosine antibodies (Transduction Laboratories, Lexington, Kentucky, USA), or with FcyRIIA (260) or Fc $\gamma$ RIIB/IC antisera followed by horseradish peroxidase-conjugated goat anti-rabbit or goat anti-mouse IgG antibodies (Santa Cruz Biotechnology Inc., Santa Cruz, California, USA). Peroxidase-labeled antibodies were detected using an ECL kit (Amersham Biosciences Europe GmbH, Orsay, France). The anti-FcyRIIA, 260 or anti-FcyRIIB/IC sera were prepared by hyperimmunization of rabbits with FcyRIIA2 (18) or with a GST fusion protein of residues from the first to the third intracytoplasmic domains of Fc $\gamma$ RIIB1, respectively (13).

Immunobistochemistry. Staining of Fc $\gamma \mathrm{RII}$ was performed on unfixed and unsaturated tissue sections from frozen tumor samples using KB61 supernatant (19) or mouse IgG1 (DAKO SA, Trappes, France) followed by alkaline phosphatase-conjugated goat antimouse IgG antibody (Jackson ImmunoResearch Laboratories Inc.). Signal was developed using an alkaline phosphatase substrate (Fast Red TR/Naphthol AS-MX; Sigma Chemical Co., St. Louis, Missouri, USA) and counterstained with Mayer's hematoxylin. 
MTT assay. Cells $\left(2 \times 10^{3}\right.$ per well $)$ were plated in triplicate into 96 -well plates and incubated at $37^{\circ} \mathrm{C}$. After the indicated periods of time, cell numbers were assessed by the MTT method (20).

In vitro growth inhibition assays. Cells were seeded into 96-well plates in medium supplemented with $1 \%$ insulin-transferrin-sodium selenite (ITS) (Sigma Chemical Co.) for 24 hours at $37^{\circ} \mathrm{C}$. In the culture medium, the FCS was replaced by ITS to avoid potential interference of xenoreactive serum IgG in the assay. Then, purified $\operatorname{IgG}$ from sera of nude mice, the same volume of material eluted from sera of SCID mice processed similarly, anti-G $\mathrm{G}_{\mathrm{D} 2} \mathrm{mAb} 7 \mathrm{~A} 4$, or control mouse IgG3 P51.1 (anti-phosphorylcholine) were added to cells for 24 hours. This was followed by a 24hour pulse with ${ }^{3} \mathrm{H}$-thymidine $(1 \mu \mathrm{Ci} /$ well; Amersham Biosciences Europe GmbH).

Statistical analysis. The in vivo comparison of tumor size between the various groups of mice was done by Student's $t$ test with ANOVA. $P$ values less than 0.05 were considered significant.

\section{Results}

Expression of Fc $\gamma R I I B 1$ by human metastatic melanoma. The expression of FcyRIIs was investigated by immunohistochemistry in metastasis from patients with melanoma. Figure 1a illustrates representative experiments, suggesting that human metastatic melanomas express Fc $\gamma$ RIIs. This expression was heterogeneous. We found that $20-50 \%$ of melanoma cells reacted with anti-Fc $\gamma$ RIIA+B mAb KB61 (patients 721 and 926) whereas others were either faintly positive (patients 212 and 193) or negative (patient 201). Out of 19 metastases tested, eight showed clear positivity by immunohistochemistry.

A cell line, 721, was derived from liver metastasis of patient 721 . The cells expressed the melanoma antigen ganglioside $\mathrm{G}_{\mathrm{D} 2}$ and MHC class II molecules (Figure 1, $\mathrm{b}$ and c) but no detectable hematopoietic markers such as CD45, CD14, CD1a, CD4, CD15, and CD20 (data not shown). They contained between 50 and 60 human chromosomes with multiple chromosomal abnormalities, including abnormalities of $1 \mathrm{p}$, but did not contain tetrasomic chromosome (Figure 1d). About $40 \%$ of cells reacted with the pan-anti-Fc $\gamma$ RII $\mathrm{mAb}$ but not with the anti-FcrRIIA specific $\mathrm{mAb}$ (Figure 1b). Double-labeling experiments showed that FcyRII-positive and -negative 721 cells expressed the melanoma marker Mel/14 (Figure 1e). These results demonstrate that the 721 line is a melanoma line and not a cell line derived from inflammatory cells or from a fusion between an inflammatory cell and a melanoma cell. Several clones were derived from the 721 line, among which 721.1 and 721.2 expressed high or undetectable levels of Fc $\gamma$ RII, respectively, but remained $\mathrm{G}_{\mathrm{D} 2}$-positive (Figure 1c).

The FcrRII isoform expressed by 721.1 cells was determined by immunoprecipitation of Fc $\gamma$ RII followed by isoform-specific Western blot analysis (13, 21). Western blot with anti-FcyRIIB/IC antibody revealed 40-kDa polypeptides in 721.1 and A375IIB1 lysates, and 36-kDa polypeptides in A375IIB2 lysate. In the same assay, the anti-Fc $\gamma$ RIIA antibody revealed 40$\mathrm{kDa}$ polypeptides only in A375IIA lysate (Figure 1f). In

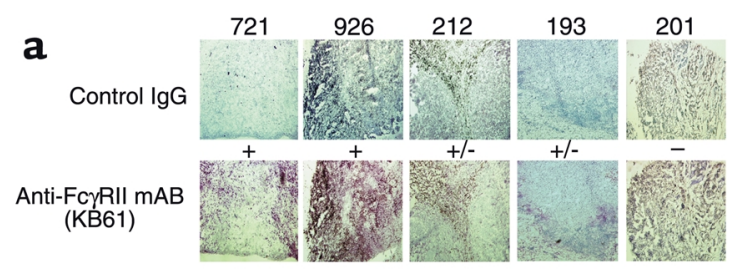

b
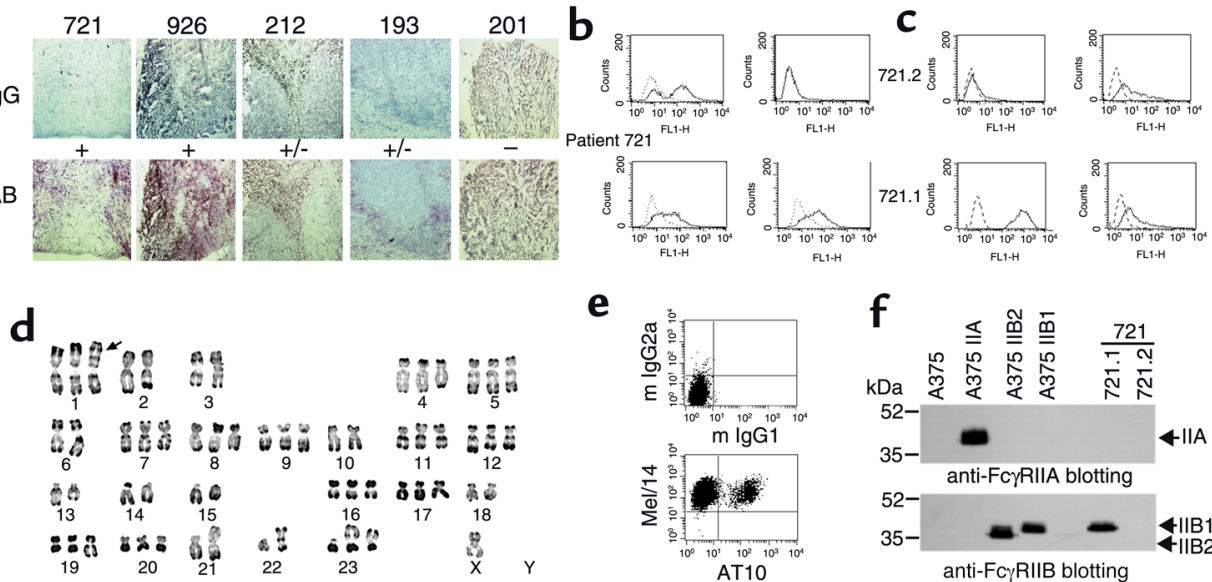

e

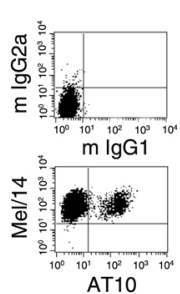

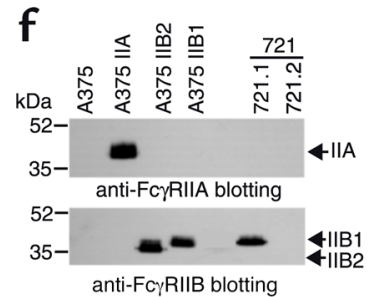

\section{Figure 1}

Human metastatic melanomas express inhibitory FcyRII. (a) Immunohistochemical analysis using anti-Fc $\gamma \mathrm{RII}$ mAb KB61 in liver (patients 721 , 926, and 212), lymph node (patient 193), or subcutaneous (patient 201) metastases from patients with cutaneous (patients 926, 193, and 201) or uveal (patients 212 and 721) melanoma (bottom). No immunostaining was detected when primary antibody was replaced with isotype control (top). $\times 30$. (b and $\mathbf{c}$ ) Cell line derived from patient 721 expresses Fc $\gamma$ RII. Cells from this melanoma line (721 and its derivative clones,

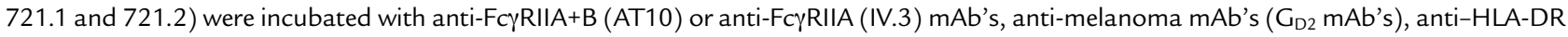
$\mathrm{mAb}$, or control isotype (dotted histograms). (d and $\mathbf{e}$ ) Cell line derived from patient 721 is a melanoma cell line. (d) R-banded karyotype of 721 cell line. Numerous structural and numerical chromosomal aberrations are present. See the abnormality of $1 p$ (arrow), probably involving $3 p$. (e) Double staining was performed by incubating cells with AT10 and anti-melanoma marker (Mel/14) mAb's (bottom) or with control isotypes (top). (f) Analysis of the FcyRII isoforms expressed by the 721 cell line, by immunoprecipitation of Fc $\gamma$ RII with AT10 in cell lysates from

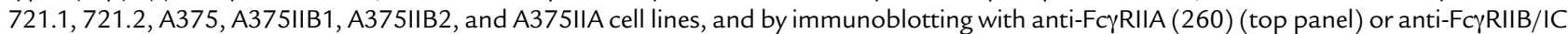
(bottom panel) polyclonal antibodies. Molecular weight standards (kDa) are shown in the left lane. mlgG, mouse IgG. 

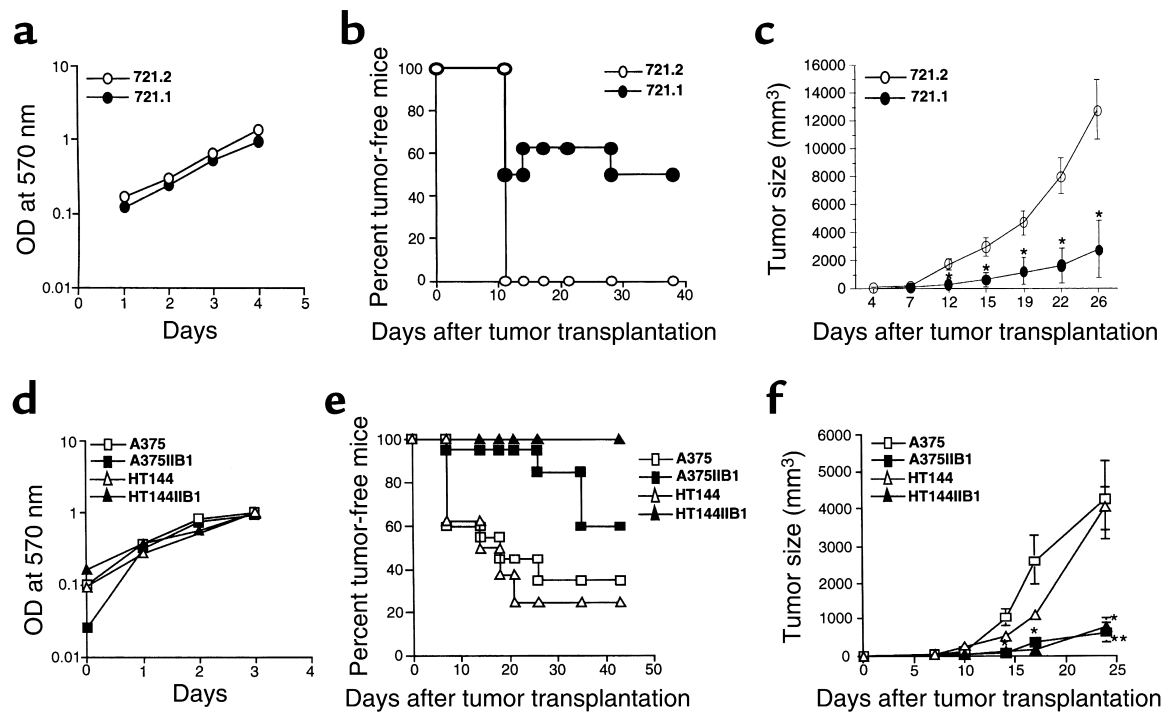

\begin{abstract}
Figure 2
FcyRIIB1 expression is associated with inhibition of development of human melanoma tumors in nude mice. (a and d) In vitro proliferation of FcyRIIB1-negative (721.2, A375, or HT144) and FcyRIIB1-positive (721.1, A375IIB1, or HT144IIB1 transfectants) melanoma lines, determined by an MTT assay on days 1-4. (b and e) Tumor uptake in nude mice, determined by subcutaneous inoculation of $2 \times 10^{6} 721.1$ and 721.2 cells $(\mathbf{b})$ or $1 \times 10^{6} \mathrm{~A} 375, \mathrm{HT} 144$, A375IIB1, or HT144IIB1 cells $(\mathbf{e})$. Results are expressed as percentage of mice $(n=30)$ that remained tumor-free after challenge in three experiments. ( $\mathbf{c}$ and $\mathbf{f}$ ) Tumor growth, measured by volume after injection of $4 \times 10^{6} 721.1$ and 721.2 cells (c) or $2 \times 10^{6} \mathrm{~A} 375, \mathrm{HT} 144, \mathrm{~A} 375 \mathrm{IIB1}$, or HT144IIB1 cells $(\mathbf{f})$. Ten mice were used per experiment in each group, and mean tumor volume values, with SD, of mice bearing tumor are shown. Data are representative of three independent experiments. ${ }^{*} P<0.03$, ${ }^{*} P<0.002$ between FcyRIIB1-positive and FcyRIIB1-negative tumors.
\end{abstract}

addition, we did not detect 36- or 40-kDa polypeptides in 721.2 lysate. Altogether, these results demonstrate that Fc $\gamma$ RIIB1 is expressed by human melanoma line 721 and its FcyRII-positive clone derivative 721.1.

Fc $\gamma$ RIIB1 inhibits growth and uptake of human melanoma in nude mice. To investigate the putative role of FcrRIIB1 on melanoma growth in vivo, 721.1 and 721.2 lines were injected subcutaneously into nude mice. As shown in Figure 2b, $100 \%$ of mice injected with FcyRIIB1-negative melanoma 721.2 developed a tumor at day 11 , whereas $50 \%$ of mice inoculated with FcrRIIB1-positive melanoma 721.1 remained tumorfree and viable at the end of the observation period (day 40). To determine the effect of Fc $\gamma$ RIIB 1 on melanoma growth, cells were grafted into nude mice at a cellular density at which no effect of Fc $\gamma$ RIIB1 was observed on tumor uptake (data not shown). Whereas both clones expanded similarly in vitro (Figure $2 \mathrm{a}$ ), the growth of FcrRIIB1-positive melanoma cells was strongly inhibited in vivo as compared with that growth of the Fc $\gamma$ RIIB1-negative clone, since up to $75 \%$ inhibition of tumor mass from day 12 to day 26 was observed $(P<0.01$ at day 26) (Figure $2 \mathrm{c}$ ). Similar results were observed using other Fc $\gamma$ RIIB1-positive and -negative clones from patient 721 (data not shown).

To demonstrate the role of FcyRIIB1, we used human metastatic melanoma transfected with cDNA encoding FcyRIIB1. Although in vitro growth kinetics of cell lines had not significantly changed after transfection (Figure 2d), a profound effect of FcyRIIB1 was seen on tumorigenicity and tumor growth, reminis- cent of our observation in cell lines from patient 721. For instance, $100 \%$ of mice inoculated with HT144IIB1 remained tumor-free and viable at the end of the observation period (day 42 ), whereas only $25 \%$ of mice injected with HT144 remained tumor-free (Figure 2e). To determine the effect of FcyRIBB1 on growth of melanoma tumors, we inoculated into nude mice a cellular dose at which no significant effect of Fc $\gamma$ RIIB1 on tumor uptake was observed $(80 \%$ and 100\% uptake of FcyRIIB1-positive and Fc $\gamma$ RIIB1-negative tumors, respectively). As shown in Figure 2f, expression of FC $\gamma$ RIIB1 led to a pronounced inhibition of growth of both A375 and HT144 melanomas starting from day 14 , up to $80 \%$ inhibition of tumor volume at day $24(P<0.001)$. Altogether, these results suggest that Fc $\gamma$ RIIB1 inhibits the uptake and growth of human melanoma cells in nude mice.

The intracytoplasmic region of Fc $\gamma$ RIIB1 is required for inhibition of growth and uptake of human melanoma in nude mice. The FcyRIIB1-mediated inhibition of cellular activation has been shown to require the receptor's cytoplasmic tail. To determine whether the intracytoplasmic region of Fc $\gamma$ RIB1 is involved in the inhibition of melanoma development in nude mice, we compared the growth of HT144 transfected with vector containing Fc $\gamma \mathrm{RIIB}\left(\mathrm{Cyto}^{-}\right)$cDNA [HT144IIB $\left(\mathrm{Cyto}^{-}\right)$] with that of HT144 and HT144IIB1. HT144IIB1 and HT144IIB $\left(\mathrm{Cyto}^{-}\right)$cell lines had similar expression levels of FcyRII (Figure 3a) and similar growth rates in vitro (Figure 3b). As shown in Figure 3c, 100\% and 75\% of mice inoculated with HT144IIB(Cyto-) or HT144, 
respectively, developed a tumor at day 42 . In contrast, $100 \%$ of mice grafted with HT144IIB1 remained tumor-free and viable over a 42-day observation period. The effect of the intracytoplasmic region of Fc $\gamma$ RIIB1 on tumor growth was then evaluated. The results showed that, from day 14 to the sacrifice of the animals at day 24, the growth of HT144IIB1 was highly and significantly inhibited (up to $80 \%$ inhibition of tumor volume) in comparison with that of HT144 or HT144IIB(Cyto $\left.{ }^{-}\right)(P<0.008)$, the growth of HT144IIB $\left(\right.$ Cyto $\left.^{-}\right)$being no different from that of HT144 (Figure 3d). Expression levels of Fc $\gamma$ RIIB were similar in the HT144IIB(Cyto-) and HT144IIB1 tumors at day 21 (Figure $3 \mathrm{e}$ ). These results indicate that the intracytoplasmic region of FC $\gamma$ RIIB1 plays a prominent role in the inhibition of development of human melanoma tumors in nude mice. In hematopoietic cells, Fc $\gamma$ RIIB-dependent negative regulation of cell proliferation requires recruitment of phosphatases by phosphorylated ITIM present in the cytoplasmic tail of FcyRIIB1. Western blot analysis of whole cell lysates showed that HT144 expressed tyrosine phosphatases SHP2 and SHP1, and the inositol phosphatase SHIP2, but not the hematopoietic lineage-specific SHIP1 (Figure 3f). Pervanadate treatment of HT144IIB1 led to recruitment of SHP2 but not of SHP1 or SHIP2 by phosphorylated Fc $\gamma$ RIB1 (Figure 3f), suggesting that FcyRIIB can be functional in human melanoma cells.

The Fc $\gamma$ RIIB1-dependent inbibition of tumor development does not occur in SCID mice. The Fc $\gamma$ RIIB1 expressed by human melanoma binds mouse IgG. Although nude mice lack a thymus, they have significant amounts of circulating IgG produced against $T$ cell-independent antigens such as gangliosides expressed by human a

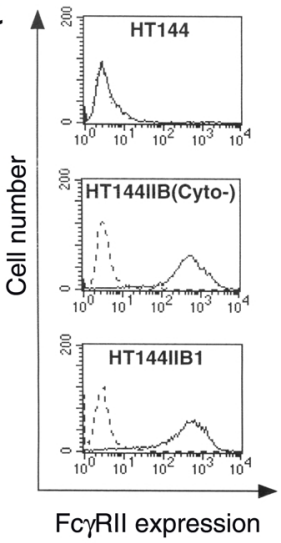

C

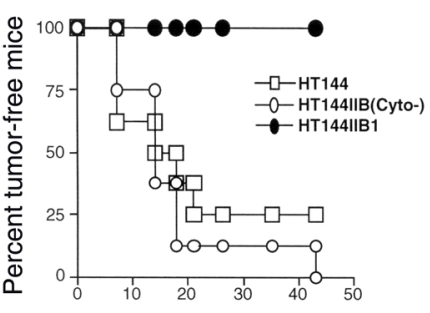

Days after tumor transplantation $\mathbf{e}$

HT144IIB1(Cyto-)

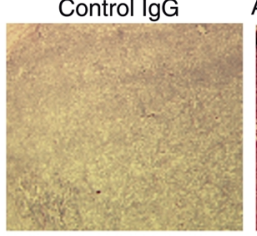

Anti-FcgRII mAb (KB81)

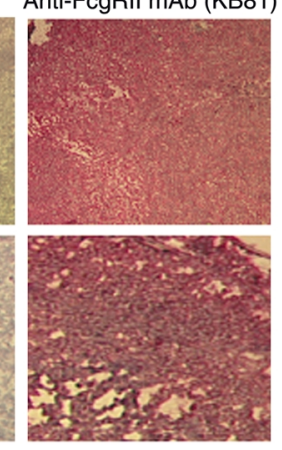

HT144IIB1

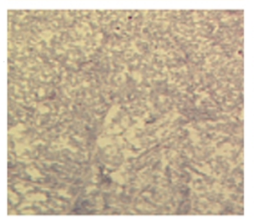

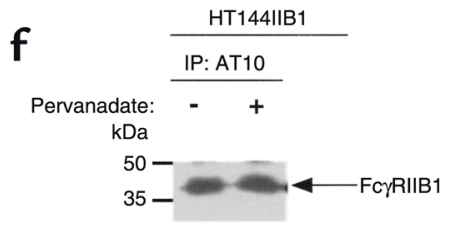

d
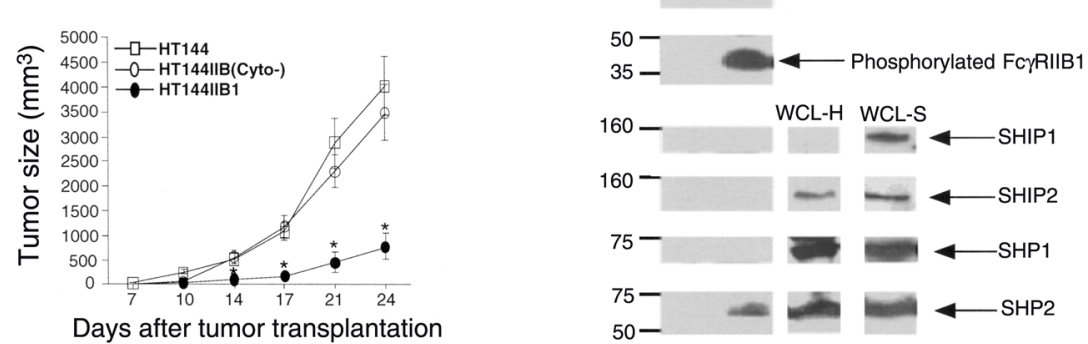

Figure 3

The FcyRIIB1-mediated inhibition of melanoma development in nude mice requires the receptor's cytoplasmic tail. HT144IIB1 and $\mathrm{HT} 144 \mathrm{IIB}\left(\mathrm{Cyto}^{-}\right)$cell lines were used. (a) Expression of FcyRIIB1 as assessed the day before injection by flow cytometry using AT10 or control IgG1 (dotted histograms). (b) In vitro proliferations of melanoma lines were determined by an MTT assay on days 1-4. (c) Tumor uptake incidence as determined by subcutaneous inoculation of nude mice with $1 \times 10^{6}$ cells. Results are expressed as percentage of mice $(n=20)$ that remained tumor-free after challenge in two experiments. (d) Tumor growth as measured by volume after inoculation of $2 \times 10^{6}$ cells. Ten mice were used per experiment in each group, and mean tumor volume values of mice bearing tumor with SDs are shown. Data are representative of two independent experiments. ${ }^{*} P<0.01$ between HT144IIB1 tumors and HT144 or HT144IIB(Cyto-) tumors. (e) Immunohistochemical analysis of FcyRII expression using KB61 mAb (right panels), on tumor tissues at day 21 after injection in nude mice of HT144IIB1 (bottom) or HT144IIB(Cyto-) (top) cells. $\times 30$. (f) Recruitment of SHP2 phosphatase to phosphorylated FcyRIIB1. HT144IIB1 cells $\left(6 \times 10^{7}\right)$ were treated or not treated with $100 \mu \mathrm{M}$ pervanadate for 10 minutes. Cells were lysed and FcyRIIB was immunoprecipitated using AT10 mAb. Immunoprecipitated materials were electrophoresed and Western blotted with anti-FcyRIIB/IC, anti-phosphotyrosine, anti-SHIP1, anti-SHIP2, antiSHP1, and anti-SHP2 Ab's. Whole cell lysates of HT144IIB1 (WCL-H) or ST486 (WCL-S) were used as positive controls. 
melanoma. To further investigate the mechanism by which FcrRIIB1 inhibits tumor development, the melanoma lines were grafted into SCID mice, which do not mount any adaptive immune response, including antibody production. As shown in Figure 4a, 100\% of SCID mice inoculated with FcrRIIB1-negative melanoma (721.2, A375, HT144) and 85\% of their Fc $\gamma$ RIIB1-positive counterparts expressing wild-type (721.1) or recombinant FcyRIIB1 (A375IIB1, HT144IIB1) developed a tumor within 13 days. No significant difference in tumor uptake was seen between HT144IIB1 and HT144IIB(Cyto-) cells (Figure $4 \mathrm{a})$. In addition, the growth rates of all three FcrRIIB1-positive tumors were similar to that of their Fc $\gamma$ RIIB1-negative counterparts, and no significant difference was found between growth of HT144IIB1 and growth of HT144IIB1 $\left(\right.$ Cyto $\left.^{-}\right)$tumors over a 31day period (Figure $4 \mathrm{~b}$ ).

Role of antibodies in the Fc $\gamma$ RIIB1-dependent inbibition of melanoma growth in vitro and in vivo. The fact that FcyRIIB1-positive human melanoma cells behaved differently in nude and SCID mice raised the possibility that IgG ICs or IgG directed against tumor cells play an important role in melanoma development in nude mice. Immunofluorescence assays were performed on Fc $\gamma$ R-negative HT144 cells to ensure that sera from nude mice contained anti-tumor IgG. Thus, sera taken at day 14 from nude mice bearing HT144IIB1 or HT144IIB $\left(\mathrm{Cyto}^{-}\right)$tumors contained IgG binding to HT144, some reactivity being also detected at day 0 (Figure 5a). IgGs isolated from the sera of nude mice bearing day-14 tumors were tested for their effect on melanoma cell proliferation after 2 days of culture.
The proliferation of HT144IIB1 but not that of HT144IIB (Cyto ${ }^{-}$cells was inhibited in a dose-dependent manner by IgG isolated from sera of nude mice bearing HT144IIB1 or HT144IIB(Cyto-) tumors (up to $40 \%$ inhibition reached at $20 \mu \mathrm{g} / \mathrm{ml} \operatorname{IgG}$ ) (Figure $5 \mathrm{~b}$ ). A high dose of IgG isolated from day-0 sera of nude mice slightly inhibited cell proliferation (25\%). Moreover, eluate from sera of SCID mice bearing tumor, treated under the same conditions, did not contain antibodies (data not shown) and failed to inhibit the proliferation of both cell lines (Figure 5b). Another HT144IIB1 clone and two other HT144IIB(Cyto-) clones gave the same results (data not shown), which indicate that antimelanoma IgGs are produced in nude mice and inhibit proliferation of Fc $\gamma$ RIIB1-positive melanoma in an intracytoplasmic-dependent manner. Since these antibodies were mainly of the IgG3 isotype (data not shown), we investigated whether mouse IgG3 bound human FcyRIIB. As shown in Figure 5c, a significant binding of mouse IgG3 was detected in HT144IIB1 and not in HT144. This binding was inhibited by AT10, suggesting that human FcyRIIB1 is responsible for it. Taken with data shown in Figure 4, these results suggest that antibodies could play a direct role in FcyRIIB1-mediated inhibition of uptake and growth of human melanoma in nude mice.

Effect of anti- $G_{D 2} m A b$ on melanoma growth in vitro and in vivo. The ganglioside $\mathrm{G}_{\mathrm{D} 2}$ is a major melanoma-associated glycolipid antigen that induces production of $\operatorname{IgG}$ in melanoma patients $(22,23) .7 \mathrm{~A} 4$ is an IgG3 $\mathrm{mAb}$ that reacts with $\mathrm{G}_{\mathrm{D} 2}$ expressed by neuroectoderm-derived tumors such as melanoma and has been used for tumor therapy. To extend the role of IgG in a

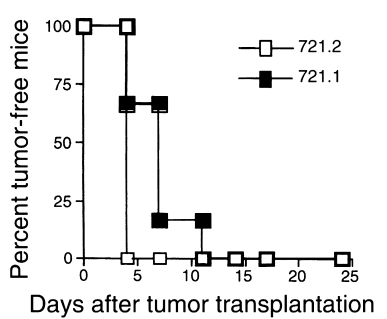

b

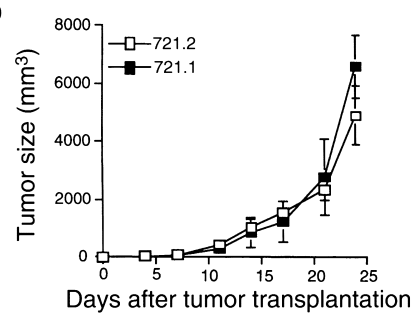

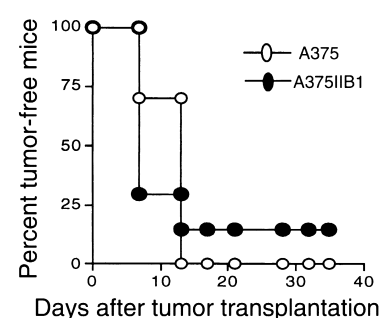

Days after tumor transplantation

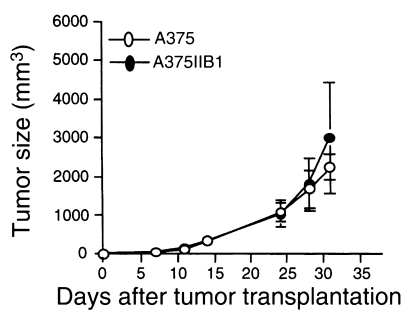

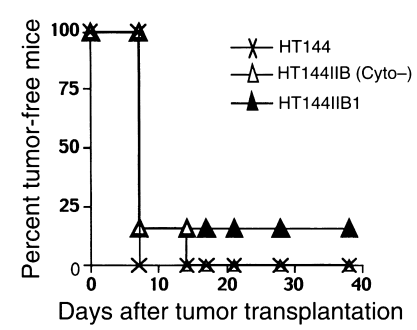

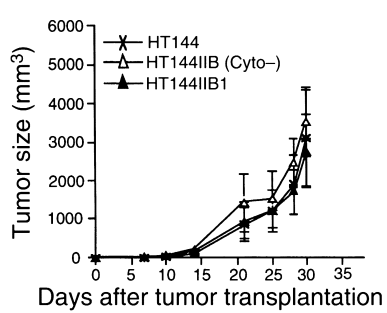

Figure 4

The development of human melanomas is independent of FCyRIIB1 expression in SCID mice. (a) Tumor uptake, determined by inoculation of $2 \times 10^{6} 721.1$ or 721.2 cells or $1 \times 10^{6} \mathrm{~A} 375$, A375IIB1, HT144, HT144IIB(Cyto-), or HT144IIB1 cells in SCID mice. Results are expressed as percentage of mice $(n=18)$ that remained tumor-free after challenge in two experiments. (b) Tumor growth, measured by volume after inoculation of $4 \times 10^{6} 721.1$ or 721.2 cells or $2 \times 10^{6}$ A375, A375IIB1, HT144, HT144IIB(Cyto-), or HT144IIB1 cells. Nine mice were used per experiment in each group, and mean tumor volume values, with SD, of mice bearing tumor are shown. Data are representative of two independent experiments. 
a

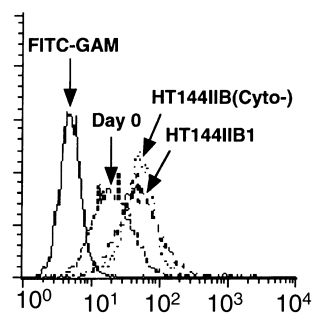

b

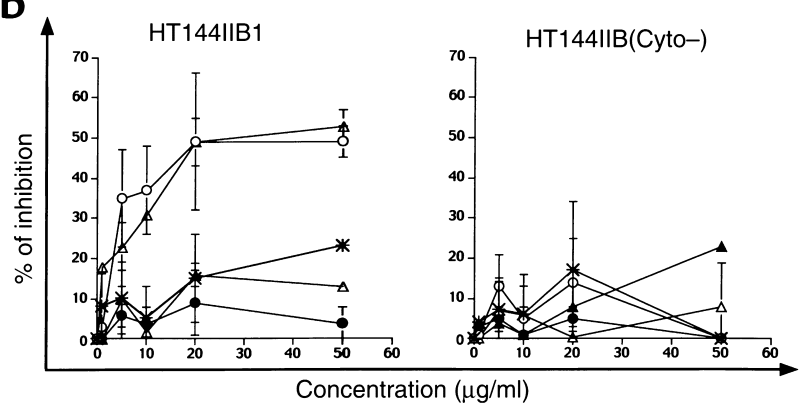

C

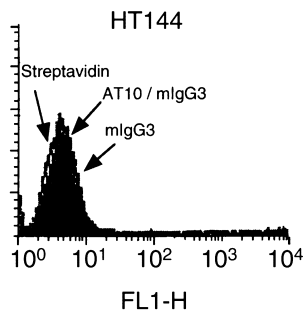

Figure 5

Sera from nude mice contain $\lg G$ antibodies that bind to melanoma cells and inhibit proliferation of FcyRIIB1-positive melanoma cells in an intracytoplasmic-dependent manner. (a) Day-0 and day-14 sera from nude mice bearing HT144IIB(Cyto-) or HT144IIB1 tumors, or medium alone (FITC-GAM), were incubated with HT144 cells, and binding of IgG was assessed by flow cytometry. (b) HT144IIB1 (left panel) or $\mathrm{HT} 144 \mathrm{IIB}\left(\mathrm{Cyto}^{-}\right)$(right panel) cells $\left(5 \times 10^{3} /\right.$ well) were incubated with the indicated concentrations of $\mathrm{IgG}$ isolated from sera of nude mice at day 0 (cross) or bearing day-14 HT144IIB1 (open circles) or $\mathrm{HT} 144 \mathrm{IIB}\left(\right.$ Cyto $^{-}$) (open triangles) tumors or with the same volume of control eluates from sera of SCID mice bearing day-14 HT144IIB 1 (filled circles) or HT144IIB (Cyto-) (filled triangles) tumors for 24 hours to FCS-free medium. This was followed by a 24-hour pulse with ${ }^{3} \mathrm{H}$-thymidine. The percentages of inhibition were estimated with the formula [(1-cpm of stimulated cells / cpm of unstimulated cells $) \times 100$ ]. Each point represents results from three independent experiments performed in triplicate (mean $\pm \mathrm{SD}$ ). (c) HT144 (left panel) or HT144IIB1 (right panel) cells were preincubated with AT10, then with biotin-labeled mouse IgG3, and then with FITC-conjugated streptavidin, or were not preincubated. Binding of mouse IgG3 was compared with background binding of FITCconjugated streptavidin.

Fc $\gamma$ RIIB1-mediated inhibition of cell proliferation, we studied the effect of 7A4 mAb on the proliferation of HT144, HT144IIB1, and HT144IIB(Cyto-) melanoma cells. These cell lines express similar levels of $\mathrm{G}_{\mathrm{D} 2}$ (Figure 6a). The proliferation of HT144IIB1 cells was significantly inhibited in a dose-dependent manner by $7 \mathrm{~A} 4 \mathrm{mAb}$ at day $2\left(50 \%\right.$ inhibition of ${ }^{3} \mathrm{H}$-thymidine incorporation at $100 \mu \mathrm{g} / \mathrm{ml}$ ), but not by control mouse IgG3, although the proliferation of HT144 and
HT144IIB (Cyto-) cells was not significantly modified (less than 20\% inhibition at the same dose) (Figure 6b). Since 7A4 seems to reproduce the Fc $\gamma$ RIIB1-dependent negative regulation of cell proliferation with IgG produced in nude mice, we investigated whether this $\mathrm{mAb}$ could be used to regulate melanoma growth in SCID mice. For this purpose, HT144IIB1 and HT144IIB $\left(\right.$ Cyto $\left.^{-}\right)$cells were injected subcutaneously into SCID mice. The intravenous injections of anti$\mathrm{G}_{\mathrm{D} 2} \mathrm{mAb}$ resulted in significant inhibition of growth of HT144IIB1 melanoma from day 6 to day 28 (up to $50 \%$ inhibition of tumor mass at day $28, P<0.0001$ ) (Figure $6 \mathrm{c}$ ). In contrast, the anti- $\mathrm{G}_{\mathrm{D} 2} \mathrm{mAb}$ failed to inhibit the growth of FcyRIB(Cyto-) melanoma (Figure $6 \mathrm{~d}$ ). Altogether, these results display that anti- $\mathrm{G}_{\mathrm{D} 2}$ mAb's are able to inhibit Fc $\gamma$ RIIB1-positive melanoma growth in vitro and in vivo and that these inhibitions require the cytoplasmic tail of Fc $\gamma$ RIIB1.

\section{Discussion}

Tumor cells present in metastasis of melanoma patients were found to express inhibitory Fc $\gamma$ RIIB as detected in situ and on tumor-derived melanoma lines. In tumor sections, melanin was clearly detected in Fc $\gamma$ RII-positive cells, and melanoma marker S100 was coexpressed with FcrRII (data not shown). The cell line derived from patient 721 had the chromosomal characteristics and cell surface marker expression of a melanoma line. Isoform-specific analysis of Fc $\gamma \mathrm{RII}$ showed that the 721 cell line expressed only Fc $\gamma$ RIB1 isoform. Other cell lines derived from Fc $\gamma$ RII-positive biopsies of liver (212 line) or cutaneous metastases (three lines) were also found to react with anti-Fc $\gamma R I-$ IA $+B$ but not with anti-Fc $\gamma$ RIIA mAb (data not shown).

Our observations of ectopic expression of Fc $\gamma$ RIIB1 by human melanoma are reminiscent of previous observations suggesting that tumor cells of nonhematopoietic origin may express low-affinity $\mathrm{Fc} \gamma \mathrm{R}$ $(10,12,24)$. None of the tumor-derived cell lines expressed Fc $\gamma$ RI or Fc $\gamma$ RIII (data not shown). Expression of FcyRII on tumor cells was heterogeneous and was found in about $40 \%$ of tested metastases. This raises the question of what mechanisms control $F c \gamma R$ expression in tumor cells. Culture of melanoma lines A375, HT144, and 721.2 in the presence of cytokines such as IFN- $\gamma$, TNF- $\alpha$, GM-CSF, and TGF- $\beta$ did not induce significant expression of FcyRII (data not shown). Moreover, the expression level of FcyR did not decrease during primary cultures of Fc $\gamma$ RII-positive melanomas and remained stable after several years in culture. Thus it is likely that the expression of Fc $\gamma \mathrm{RII}$ is an intrinsic property of tumor cells. It is possible that IgG-containing ICs may upregulate Fc $\gamma$ RII expression during the primary stages of tumor formation, as previously observed in vitro on cell lines of lymphoid origin (25).

A prominent and significant inhibitory role of FcyRIIB1 in tumor development was found to occur in nude but not in SCID mice. This inhibition was 
a

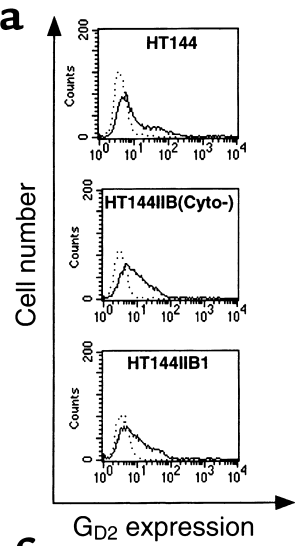

C

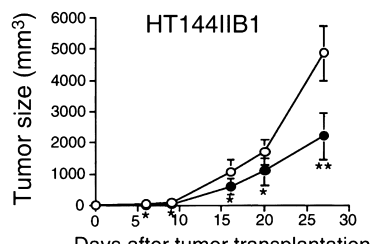

Days after tumor transplantation

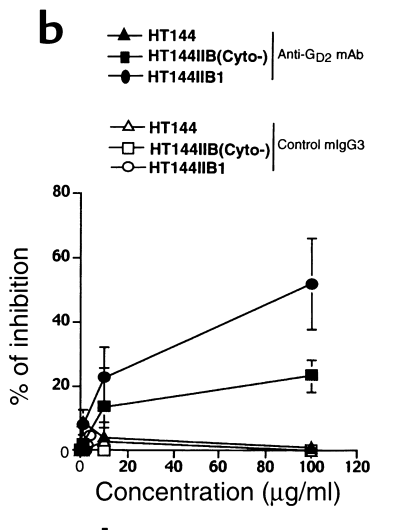

d

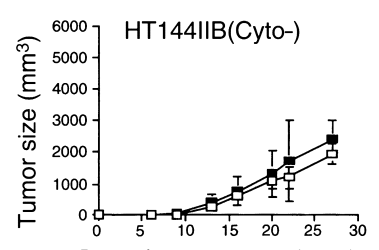

Days after tumor transplantation

\section{Figure 6}

Anti-G $\mathrm{D}_{2} \mathrm{mAb}$ inhibits growth of FcyRIIB1-positive tumor cells in vitro and in vivo, in an intracytoplasmic-dependent manner. (a) Expression of $G_{D 2}$ on cells as assessed by flow cytometry using 7A4 or a control isotype (dotted histograms). (b) Inhibition of proliferation of melanoma cells in vitro. Cells $\left(5 \times 10^{3}\right.$ cells per well $)$ were incubated with the indicated concentrations of anti-G $\mathrm{D}_{2} \mathrm{mAb} 7 \mathrm{~A} 4$ (filled symbols) or control mouse IgG3 (open symbols). ${ }^{3} \mathrm{H}$-thymidine incorporation rate and percentages of inhibition were measured as described in Figure 5. Each point represents results from three independent experiments performed in triplicate (mean \pm SD). (c and d) Inhibition of growth of HT144IIB1 but not of HT144IIB(Cyto-) tumors in SCID mice injected intravenously with anti-G $G_{D 2} \mathrm{mAb}$. SCID mice were inoculated subcutaneously with $2 \times 10^{6} \mathrm{HT} 144 \mathrm{IIB} 1$ (c) and $\mathrm{HT} 144 \mathrm{IIB}\left(\mathrm{Cyto}^{-}\right)$(d) cells, followed by biweekly intravenous injections of $50 \mu \mathrm{g}$ of mAb 7A4 (filled symbols) or PBS (open symbols). Eight mice were used per experiment in each group, and mean tumor volume values, with SD, of mice bearing tumor are shown. ${ }^{*} P<0.05,{ }^{*} P<0.0001$.

observed by using two FcyRIIB1-positive and two Fc $\gamma$ RIIB1-negative clones independently derived from 721 melanoma. The in vivo growth properties of the noncloned cell lines (A375 and HT144) transfected or not transfected with cDNA encoding FcrRIIB1 showed the same results (data not shown). These results strongly suggest that this phenomenon is not due to cellular variants occurring during cell culture. We found that nude mice develop mostly antibodies of the IgG3 isotype (data not shown), some of which react with melanoma antigens. These antibodies are most likely directed against the carbohydrate antigens expressed by melanoma cells, which may act as T-independent antigens in this system. Addition of IgG, isolated from sera of nude mice bearing tumor, led to a significant inhibition of proliferation of HT144 melanoma cells expressing whole FcyRIIB1 but not FcyRIIB(Cyto-). Small amounts of IgG binding to melanoma cells were detected in nude mice before

tumor injection that slightly inhibited HT144IIB1 cell proliferation in vitro. Such IgG may be responsible for inhibition of uptake of Fc $\gamma$ RIIB1-positive tumors during the first stages of tumor development.

The fact that growth of HT144IIB(Cyto $\left.{ }^{-}\right)$tumors was similar to that of HT144 in nude mice and was not inhibited by anti- $\mathrm{G}_{\mathrm{D} 2}$ in SCID mice reflects, most probably, the low capacity of mouse IgG3s both to activate complement in vivo (26) and to trigger ADCC, a deficiency that results from their inability to bind mouse FcrR expressed by mouse effector cells such as macrophages (data not shown) and NK cells (27). Several mechanisms might be responsible for the in vitro and in vivo FcyRIBB1 intracytoplasmicdependent inhibition of melanoma's growth. Mouse IgG3 in the form of complexes indeed binds to human FcyRIIB1. The recruitment of SHP2 tyrosine phosphatase by phosphorylated FcrRIB1 in HT144 cells suggests that human Fc $\gamma$ RIIB1 can be fully active in human malignant melanoma. In a chicken B cell line, Fc $\gamma$ RIIB1 mediates an apoptotic response upon homoaggregation, independently of its cytoplasmic region (28). One possibility is that ICs act similarly on melanoma cells. However, aggregation of Fc $\gamma$ RIIB1 had no effect on proliferation of Fc $\gamma$ RIIB1-positive melanoma in vitro (data not shown). An alternative hypothesis is that antibodies directed against melanoma antigens or growth factor receptors may recruit Fc $\gamma$ RIIB1 into cell activation units. It has been reported that $\mathrm{G}_{\mathrm{D} 2}$ and ErbB2 localize in membrane microdomains $(29,30)$ and that activated tyrosine kinase receptors (such as c-kit) are sensitive to FcrRIIB1 inhibitory signals (31). Thus one possible explanation is that cross-linking of Fc $\gamma$ RIB 1 to such molecules brings the signaling molecules required for inhibitory activity toward the microdomains, as recently observed when Fc $\gamma$ RIIB1 is coaggregated to the $\mathrm{B}$ cell receptor (32). We tested this hypothesis in preliminary experiments. Although no significant Fc $\gamma$ RIIB1 phosphorylation was detected using anti$G_{D 2}$ or nude mouse antibodies, cross-linking of FcrRIIB1 and ErbB2 with anti-ErbB2 mAb induced phosphorylation of FcyRIIB1 and recruitment of SHP2 by phosphorylated Fc $\gamma$ RIBB1. Interestingly, antiErbB2 $\mathrm{mAb}$ also inhibited the in vitro proliferation of FcyRIIB1-positive human metastatic melanoma lines in an Fc-dependent manner (data not shown).

The $\mathrm{T}$-independent anti-tumor IgG produced in nude mice may also be directed against ganglioside $G_{D 2}$ or other raft-localized antigens. While anti- $G_{D 2}$ $\mathrm{mAb}$ 's and antibodies specific for xenoreactive antigens may indeed have an Fc $\gamma$ RIIB1-inhibitory role, it remains to be seen whether this role is shared by antibodies with other specificities, particularly those produced in syngeneic hosts.

The anti-CD20 and anti-ErB2 mAB's which were generated in xenogeneic hosts, currently represent therapeutic options against lymphoma (5) and cancers of nonhematopoietic origin (33), respectively. In vivo 
study has indicated that ADCC may be important for antitumor activities of these mAb's (9). The present work raises the possibility that, in addition to their well-documented activity via Fc $\gamma$ R-positive host effector cells, antibodies may act directly via Fc-dependent pathway on tumor cells. Since antibody-mediated therapies showed some efficacy only in some groups of treated patients (34), it is likely that unknown mechanisms of action are behind these effects and these variable responses. Our data support an alternative hypothesis for the efficacy of therapeutic antibodies, depending on inhibitory receptor Fc $\gamma$ RIIB 1 expression on tumor cells.

\section{Acknowledgments}

We thank K. Pulford, D. Rimoldi, C. Anderson, J.G. Van de Winkel, J. Michon, and J.L. Teillaud for kindly providing antibodies; I. Isnardi, R. Lesourne, and O. Malbec for helpful advice; and M. Daëron for giving us Fc $\gamma$ RII constructs. We also thank C. Dubois-d'Enghein and A. Nicolas at Institut Curie for technical assistance. This work was supported by grants from the Association pour la Recherche contre le Cancer (ARECA), the Ligue Nationale de Lutte contre le Cancer, and INSERM. L. Cassard and J.F.G. Cohen-Solal were the recipients of a fellowship from the Ministère de la Recherche.

1. Ravetch, J.V., and Bolland, S. 2001. IgG Fc receptors. Annu. Rev. Immunol. 19:275-290.

2. Amigorena, S., et al. 1992. Cytoplasmic domain heterogeneity and functions of IgG Fc receptors in B lymphocytes. Science. 256:1808-1812.

3. Van den Herik-Oudijk, I.E., Capel, P.J., van der Bruggen, T., and Van de Winkel, J.G. 1995. Identification of signaling motifs within human Fc gamma RIIa and Fc gamma RIIb isoforms. Blood. 85:2202-2211.

4. Fridman, W.H., et al. 1992. Structural bases of Fc gamma receptor functions. Immunol. Rev. 125:49-76.

5. White, C.A., Weaver, R.L., and Grillo-Lopez, A.J. 2001. Antibody-targeted immunotherapy for treatment of malignancy. Annu. Rev. Med. 52:125-145.

6. Safa, M.M., and Foon, K.A. 2001. Adjuvant immunotherapy for melanoma and colorectal cancers. Semin. Oncol. 28:68-92.

7. Clynes, R., Takechi, Y., Moroi, Y., Houghton, A., and Ravetch, J.V. 1998. Fc receptors are required in passive and active immunity to melanoma. Proc. Natl. Acad. Sci. USA. 95:652-656.

8. van de Winkel, J.G., Bast, B., and de Gast, G.C. 1997. Immunotherapeutic potential of bispecific antibodies. Immunol. Today. 18:562-564.

9. Clynes, R.A., Towers, T.L., Presta, L.G., and Ravetch, J.V. 2000. Inhibitory Fc receptors modulate in vivo cytoxicity against tumor targets. Nat. Med. 6:443-446.

10. Braslawsky, G.R., Yaackubowicz, M., Frensdorff, A., and Witz, I.P. 1976. Receptors for immune complexes on cells within a non-lymphoid murine tumor. J. Immunol. 116:1571-1578.

11. Dorval, G., Witz, I.P., Klein, E., and Wigzell, H. 1976. Tumor-bound immunoglobulins. I. Further analysis of the characteristics of binding of immunoglobulins to in vivo-grown tumor cells. Int. J. Cancer. 17:109-119.
12. Ran, M., et al. 1991. In vivo acquisition of Fc gamma RII expression on polyoma virus-transformed cells derived from tumors of long latency. Cancer Res. 51:612-618.

13. Cassard, L., et al. 2000. Expression of low-affinity Fc gamma receptor by a human metastatic melanoma line. Immunol. Lett. 75:1-8.

14. Greenman, J., et al. 1991. Characterization of a new monoclonal anti-Fc gamma RII antibody, AT10, and its incorporation into a bispecific $\mathrm{F}\left(\mathrm{ab}^{\prime}\right) 2$ derivative for recruitment of cytotoxic effectors. Mol. Immunol. 28:1243-1254.

15. Gross, N., Beck, D., Portoukalian, J., Favre, S., and Carrel, S. 1989. New anti-GD2 monoclonal antibodies produced from gamma-interferontreated neuroblastoma cells. Int. J. Cancer. 43:665-671.

16. Looney, R.J., Abraham, G.N., and Anderson, C.L. 1986. Human monocytes and U937 cells bear two distinct Fc receptors for IgG. J. Immunol. 136:1641-1647.

17. Carrel, S., Accola, R.S., Carmagnola, A.L., and Mach, J.P. 1980. Common human melanoma-associated antigen(s) detected by monoclonal antibodies. Cancer Res. 40:2523-2528.

18. Astier, A., et al. 1994. Human epidermal Langerhans cells secrete a soluble receptor for IgG (Fc gamma RII/CD32) that inhibits the binding of immune complexes to Fc gamma R+ cells. J. Immunol. 152:201-212.

19. Pulford, K., et al. 1986. A new monoclonal antibody (KB61) recognizing a novel antigen which is selectively expressed on a subpopulation of human B lymphocytes. Immunology. 57:71-76.

20. Mosmann, T. 1983. Rapid colorimetric assay for cellular growth and survival: application to proliferation and cytotoxicity assays. J. Immunol. Methods. 65:55-63.

21. Pricop, L., et al. 2001. Differential modulation of stimulatory and inhibitory Fc gamma receptors on human monocytes by Th1 and Th2 cytokines. J. Immunol. 166:531-537.

22. Watanabe, T., et al. 1982. Human melanoma antigen AH is an autoantigenic ganglioside related to GD2. J. Exp. Med. 156:1884-1889.

23. Cahan, L.D., Irie, R.F., Singh, R., Cassidenti, A., and Paulson, J.C. 1982. Identification of a human neuroectodermal tumor antigen (OFA-I-2) as ganglioside GD2. Proc. Natl. Acad. Sci. USA. 79:7629-7633.

24. Elder, D.E., et al. 1989. Antigenic profile of tumor progression stages in human melanocytic nevi and melanomas. Cancer Res. 49:5091-5096.

25. Neauport-Sautes, C., Daeron, M., Teillaud, J.L., Blank, U., and Fridman, W.H. 1986. The occurrence, structural and functional properties of immunoglobulin Fc receptors on murine neoplastic cells. Int. Rev. Immunol. 1:237-271.

26. Azeredo da Silveira, S., et al. 2002. Complement activation selectively potentiates the pathogenicity of the $\operatorname{IgG} 2 \mathrm{~b}$ and $\operatorname{IgG} 3$ isotypes of a high affinity anti-erythrocyte autoantibody. J. Exp. Med. 195:665-672.

27. Hulett, M.D., and Hogarth, P.M. 1994. Molecular basis of Fc receptor function. Adv. Immunol. 57:1-127.

28. Pearse, R.N., et al. 1999. SHIP recruitment attenuates Fc gamma RIIBinduced B cell apoptosis. Immunity. 10:753-760.

29. Kalka, D., von Reitzenstein, C., Kopitz, J., and Cantz, M. 2001. The plasma membrane ganglioside sialidase cofractionates with markers of lipid rafts. Biochem. Biophys. Res. Commun. 283:989-993.

30. Zhou, W., and Carpenter, G. 2001. Heregulin-dependent translocation and hyperphosphorylation of ErbB-2. Oncogene. 20:3918-3920.

31. Malbec, O., Fridman, W.H., and Daeron, M. 1999. Negative regulation of c-kit-mediated cell proliferation by Fc gamma RIIB. J. Immunol. 162:4424-4429.

32. Aman, M.J., Tosello-Trampont, A.C., and Ravichandran, K. 2001. Fc $\gamma$ RIIB1/SHIP-mediated inhibitory signaling in B cells involves lipid rafts. J. Biol. Chem. 276:46371-46378.

33. Hudziak, R.M., et al. 1989. p185HER2 monoclonal antibody has antiproliferative effects in vitro and sensitizes human breast tumor cells to tumor necrosis factor. Mol. Cell. Biol. 9:1165-1172.

34. Scott, A.M., and Welt, S. 1997. Antibody-based immunological therapies. Curr. Opin. Immunol. 9:717-722. 